\section{Reliability, validity and psychometric properties of the Greek translation of the posttraumatic stress disorder scale}

\author{
Konstantinos Kontoangelos,, ,2 \\ Sofia Tsiori, ${ }^{1}$ Garyfalia Poulakou, ${ }^{3}$ \\ Konstantinos Protopapas, ${ }^{3}$ \\ Ioannis Katsarolis, ${ }^{3}$ Vissaria Sakka, ${ }^{3}$ \\ Dimitra Kavatha, ${ }^{3}$ \\ Antonios Papadopoulos, 3 \\ Anastasia Antoniadou, ${ }^{3}$ \\ Charalambos C. Papageorgiou1,2
}

1First Department of Psychiatry, Eginition Hospital, School of Medicine, University of Athens; 2University Mental Health Research Institute, Athens;

${ }^{3}$ Fourth Department of Internal Medicine, Attikon University Hospital, Athens, Greece

\begin{abstract}
The Greek version of the Davidson Trauma Scale (DTS) was developed to respond to the need of Greek-speaking individuals. The translated questionnaire was administered to 128 HIV outpatients (aged $37.1 \pm 9.1$ ) and 166 control patients (aged $32.4 \pm 13.4$ ). In addition to the DTS Greek scale, subjects were assessed with two other scales useful for assessing validity. For each factor analyses two components were extracted, based on Cattell's scree test. The two components solution accounted for $55.34 \%$ of the total variation in case of frequency variables and $61.45 \%$ in case of severity variables. The Cronbach's alpha coefficient and Guttman split-half coefficient of the DTS scale were 0.93 and 0.88 respectively. The test-retest reliability of the Greek version of DTS scale proved to be satisfactory. Individual items had good intra-class correlation coefficients higher than 0.5 , which means that all questions have high levels of external validity. The psychometric strength of interview for posttraumatic stress disorder-Greek version it's reliable for its future use, particularly for screening subjects with possible diagnosis of posttraumatic stress disorder.
\end{abstract}

\section{Introduction}

The structured interview for posttraumatic stress disorder (PTSD) was first developed and tested with reference to Davidson Trauma Scale (DSM)-III. The scale has been recognized as one of the several interview-based measures of PTSD for diagnosis, assessment of symptom severity and treatment effectiveness. ${ }^{1}$ Its primary purpose is to measure symptoms' frequency and severity and to evaluate treatment, for example measurement of symptom change over time, response prediction, and evaluation of differences between therapy, modalities in a research setting. ${ }^{2}$

The scale comprises of 17 items reflecting the DSM-IV criteria for PTSD, supplemented by two measures of survival and behavior guilt. 3 The structured interview has served both as a symptom severity instrument and as a diagnostic tool and has been designed to evaluate symptoms of PTSD in individuals with a history of trauma. ${ }^{4}$ Each item is rated on $0-4$ scale and represents a composite of frequency, severity and fictional impairment. Items can been categorized as follows: items $1-4$, criteria B (intrusive re-experiencing); items 5-11, criteria $\mathrm{C}$ (avoidance and numbness); and ietems 12-16, criteria D (hyper arousal). For each item, the subject rates both frequency and severity during the previous week on a point 5-point ( 0 to 4 ) scale with a maximum score of 136 point. Subscale scores can be computed separately for frequency and severity. 5 The aim of the current study was to assess the reliability, validity and psychometric qualities of the Greek translation of the posttraumatic Stress Disorder Scale.

\section{Materials and Methods}

The Davidson Trauma Scale (DTS) is a scale used in diagnosing and measuring symptom severity and treatment outcome in post-traumatic stress disorder (PTSD). 5 The Davidson Trauma Scale (DTS) is a 17 -item self-rating scale that takes respondents only 10 minutes to complete. Each one of the 17 items corresponds to a DSM-IV symptom of PTSD, ${ }^{6}$ and each symptom is rated on 5point frequency $(0=n o t$ at all to $4=$ every day) and severity Likert scales $(0=$ not at all distressing to 4=extremely distressing). Respondents are asked to identify the trauma that is most disturbing to them and to rate, in the past week, how much trouble they have had with each symptom. From Davidson Trauma Scale (DTS) we can calculate a frequency score (range: 0-68), severity score (range: 0-68), and total score (range: 0-136). It can be used to make a preliminary determination about whether the symptoms meet DSM criteria for PTSD.

Two psychiatrists who are proficient in both English and Greek translated DTS into Greek. Then another psychiatrist independently translated the items of the Greek ver-
Correspondence: Konstantinos Kontoangelos, Athens University Medical School, 1st Department of Psychiatry, Eginition Hospital, 74 Vas. Sofias Avenue, 11528, Athens, Greece. Tel.: +30.210.7289189 - Fax: +30.210.7242020 E-mail: kontange@hol.gr

Key words: Posttraumatic stress disorder; reliability; validity; HIV.

Acknowledgments: the authors would like to thank the staff of 4th Department of Internal Medicine, Athens University Medical School, Attikon University Hospital, for their valuable cooperation for the recruitment of participants. They would also like to thank the participants of the present study for their generous contribution.

Contributions: KK, acquisition of data, analysis and interpretation of data, first draft of the manuscript; ST, GP, KP, IK, VS, DK, study concept and design, interpretation of data, drafting and critical revision of the manuscript for important intellectual content; AP, acquisition of data and critical review of the manuscript for important intellectual content; AA, interpretation of data and critical review of the manuscript for important intellectual content; $\mathrm{CP}$, study concept and design, acquisition and interpretation of the data, drafting and critical revision of the manuscript, overall supervision.

Conflict of interest: the authors declare no potential conflict of interest.

Received for publication: 11 August 2016

Revision received: 21 September 2016.

Accepted for publication: 21 September 2016.

This work is licensed under a Creative Commons Attribution-NonCommercial 4.0 International License (CC BY-NC 4.0).

(C) Copyright K. Kontoangelos et al., 2017

Licensee PAGEPress, Italy

Mental Illness 2017; 9:6832

doi:10.4081/mi.2017.6832

sion of DTS back to English (back translation). The back-translated version was reviewed in order to establish whether is consistent with the original English version and thus the final Greek version of DTS was obtained.

In additional to the DTS Greek scale, subjects were assessed with two other scales useful for assessing validity. For criterion based validity, the SCL-90 and EPQ scales was administered as an independent valuators. Psychometric Personality scale of extraversion, neuroticism, psychotism (Eysenck Personality Questionnaire, EPQ). ${ }^{7}$ The Eysenck personality questionnaire consists of 84 entries evaluated by the patient with a yes or no. The purpose of this 
questionnaire is to explore four dimensions of personality: psychotism $(\mathrm{P})$, neuroticism (N) extraversion (E) and lying (L). The scales $\mathrm{N}$ and $\mathrm{L}$ are of particular clinical interest. The $\mathrm{N}$ scale is the best studied and is associated with a clinical diagnosis of neurosis or oral personalities according to psychoanalytic terminology. The E scale corresponds roughly to histrionic personalities. The P scale corresponds to obsessivecompulsive personalities and is unrelated to psychosis. Finally, the L scale controls the degree of hypocrisy of the examined party but can also be high in patients with psychosomatic disorders who are not pretending. A weighted Greek version is available. ${ }^{8}$ Psychometric general psychosomatic burden scale (SCL-90). 9 The SCL-90 questionnaire is self-completed and measures 9 psychopathology parameters (as many as its subscales), which are: i) somatization, ii) depression, iii) anxiety, iv) phobic anxiety, v) obsessive compulsive, vi) paranoid ideation, vii) psychoticism viii) hostility, ix) interpersonal sensitivity. The questionnaire includes 90 questions in total. All entries are rated from 0 to 4 , giving a total score of 360. The scale is used to extrapolate 3 aggregate indexes: i) the general gravity index, ii) the positive symptoms distress index, iii) the set of positive symptoms. A weighted Greek version is available. 10

The translated questionnaire was administered to 128 HIV outpatients aged 37.1 \pm 9.1 (range: 17-64) (76 male and 52 female) and 166 controls (98 male and 68 female) aged 32.4 \pm 13.4 (range: 19-92).

The present study was conducted at the Attikon University Hospital and the sample was randomly selected from Patients came from the Infectious Diseases unit of the Attikon Hospital, Athens, Greece. All sub- jects complete the questionnaires by themselves. The average time to complete the questionnaires was 30 minutes.

\section{Statistical analysis}

All statistical analyses were carried out with IBM SPSS Statistics V20.0 and we use 5\% significant levels for all statistical tests. Explanatory factor analysis was contacted to investigate the factor structure and dimensionality of the 17-items Greek version of DTS scale. ${ }^{11}$ Two components were extracted, based on Cattell's scree test. Cronbach's alpha, ${ }^{12}$ and Guttman split-half coefficient ${ }^{13}$ were used to evaluate interval consistency of DTS scale and of the two factors extracted for principal component analysis, in 294 subjects. A subgroup of subjects completed the questionnaire for a second time, one week later, in order to assess test-retest reliability. Intra-class cor-

Table 1. Mean scores (range 0-10), standard deviation (SD) and communalities for each item of the scale.

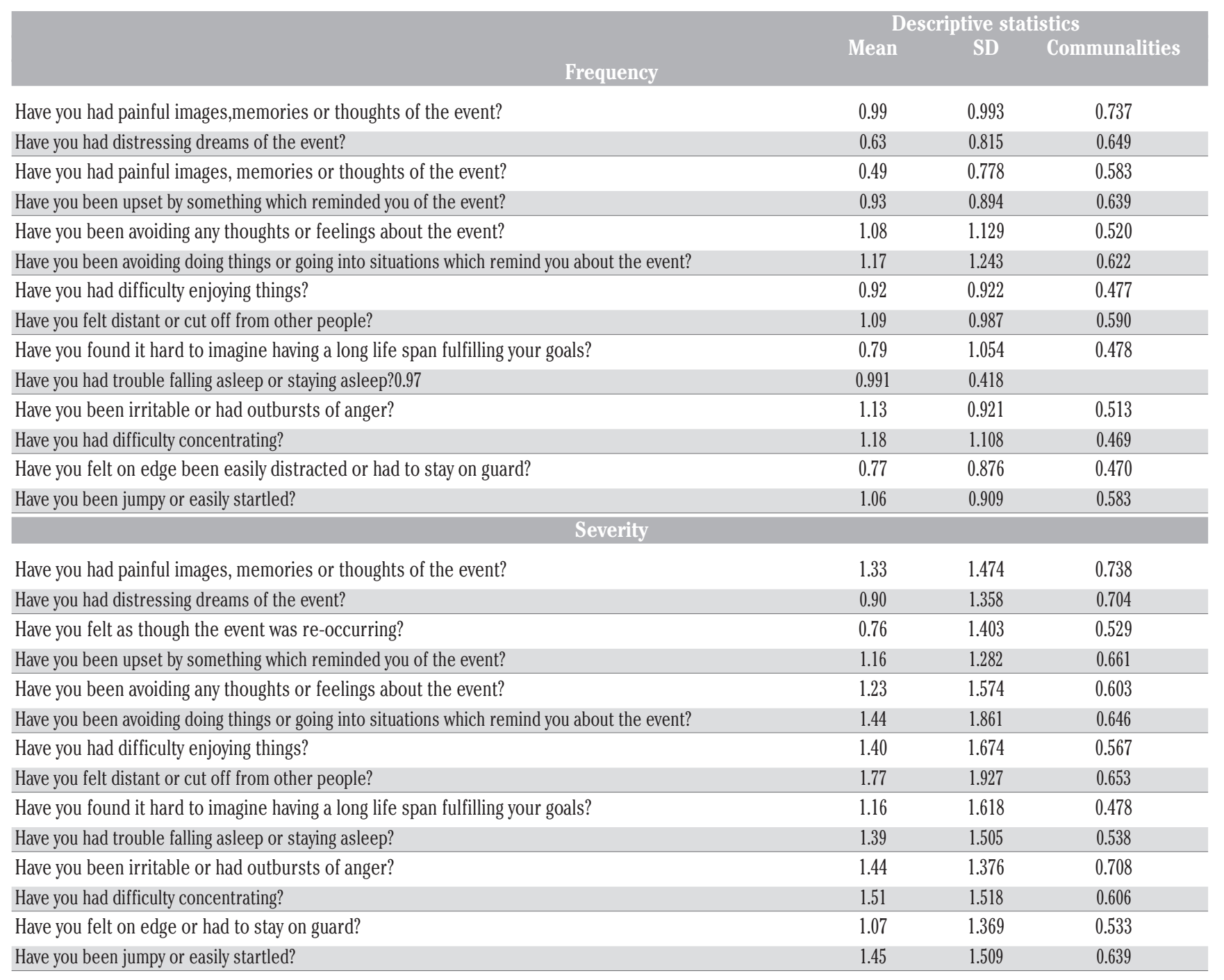


Table 2. Pattern matrix of extract factors.

\begin{tabular}{|c|c|c|c|c|}
\hline & Frer & & & \\
\hline & Factor 1 & Factor 2 & Factor 1 & Factor 2 \\
\hline Have you had painful images, memories or thoughts of the event? & 0.014 & 0.851 & -0.024 & 0.874 \\
\hline Have you had distressing dreams of the event? & -0.057 & 0.836 & -0.114 & 0.91 \\
\hline Have you felt as though the event was re-occurring? & 0.012 & 0.757 & -0.07 & 0.771 \\
\hline Have you been upset by something which reminded you of the event? & 0.11 & 0.732 & 0.083 & 0.756 \\
\hline Have you been avoiding any thoughts or feelings about the event? & -0.054 & 0.75 & 0.225 & 0.609 \\
\hline $\begin{array}{l}\text { Have you been avoiding doing things or going into situations which } \\
\text { things or going into situations which remind you about the event? }\end{array}$ & -.012 & 0.795 & 0.187 & 0.668 \\
\hline Have you had difficulty enjoying things? & 0.677 & 0.023 & 0.673 & 0.113 \\
\hline Have you felt distant or cut off from other people? & 0.776 & -0.014 & 0.738 & 0.1 \\
\hline Have you found it hard to imagine having a long life span fulfilling your goals? & 0.687 & 0.008 & 0.624 & 0.097 \\
\hline Have you had trouble falling asleep or staying asleep? & 0.567 & 0.125 & 0.718 & 0.023 \\
\hline Have you been irritable or had outbursts of anger? & 0.765 & -0.093 & 0.91 & -0.109 \\
\hline Have you had difficulty concentrating? & 0.756 & -0.143 & 0.828 & -0.078 \\
\hline Have you felt on edge, or had to stay on guard? & 0.594 & 0.143 & 0.687 & 0.064 \\
\hline Have you been jumpy or easily startled? & 0.683 & 0.128 & 0.804 & -0.008 \\
\hline
\end{tabular}

relation coefficients for the total score and each independent question was used to investigate the consistency between the two measurements. ${ }^{14}$ Criterion based validity was evaluated by calculated Spearman's rho correlation coefficients between the score of DTS-Greek scale and of SCL-90 and EPQ scales and subscales.

\section{Results}

\section{Factor analysis}

Principal components analyses using Promax oblique rotation with a Kappa of 4 was performed on 294 individuals also for frequency variables and for severity variables. Variables 7, 10 and 17 do not fit well with the factor solutions and dropped from both analyses. Both factor analyses based on the correlation matrix. Kaiser-MeyerOlkin Measure of Sampling Adequacy (KMO) was 0.900 for frequency variables and 0.924 for severity variables hence suggesting a high factorability for the sample. Bartlett's Test of Sphericity rejected the null hypothesis of an identity matrix in both factor analyses (frequency: $\chi^{2}=1881.595$, $\mathrm{df}=91$ and $\mathrm{P} \leq 0.0001$; severity: $\chi^{2}=2417.663, \mathrm{df}=91$ and $\left.\mathrm{P} \leq 0.0001\right)$ In Table 1, extracted communalities were fairly high in both factor analyses. This, in combination with the fact that extracted factors were well determined suggests that the sample size was adequate. For each factor analyses two components were extracted, based on Cattell's scree test. The two components solution accounted for $55.339 \%$ of the total variation in case of frequency vari-

Table 3. Consistency of DTS scale and sub-scales.

\begin{tabular}{lccc} 
& Items & Cronbach's $\alpha$ & Guttman split-half coefficient \\
DTS scale & $1-17$ & 0.930 & 0.878 \\
Factors & & & \\
1 & 1.2 .3 .4 .5 .6 & 0.886 & 0.807 \\
2 & 8.9 .11 .12 .13 .14 .15 .16 & 0.890 & 0.839 \\
\hline
\end{tabular}

ables and $61.455 \%$ in case of severity variables. Initial eigenvalues of the two components were: factor $1=6.128$ and factor $2=1.619$ in case of frequency variables and factor $1=7.306$ and factor $2=1.298$ in case of severity variables. Table 2, for both analyses, presents which item load on the two components. As we can see, the 1, 2, 3, 4, 5 and 6 loading in factor 1 . Factor 2 contained the items $8,9,11,12,13,14,15$ and 16.

\section{Validity and reliability of DTS scale}

\section{Interval consistency reliability}

Interval consistency of DTS scale in 294 individuals was evaluated by Cronbach's alpha and Guttman split-half coefficient (Table 3). Cronbach's alpha coefficient averages the inter-correlations between all the items in a particular test or sub-scale to give some indication of the extent to which a scale hangs together as a measure of a single dimension. Split-half reliability is another form of internal consistency reliability. In split-half reliability we randomly divide all items into two sets and we calculate the total score for each randomly divided half. A basic assumption of split-half reliability is that the two halves of the test should yield similar true scores and error variances. Guttman split-half coefficient needs to be more than 0.80 to be acceptable. The Cronbach's alpha coefficients and Guttman split-half coefficient of the DTS scale were 0.930 and 0.878 respectively. The corresponding values for the sub-scales are presenting in Table 3.

\section{Test-retest}

In order to investigate whether the DTS scale is influenced by external factors, we used the test-retest method. Of the total 294 individuals participated in the study and initially answered the questionnaire. 98 were those who completed the questionnaire for a second time after one week. For each item the consistency between the two measurements was evaluated by intra-class correlation coefficients. Values equal to 0.40 give the distinction point between sufficient and insufficient reliability. The test-retest reliability of the Greek version of DTS scale proved to be satisfactory. Individual items had good intra-class correlation coefficients higher than the 0.5 (Table 4) which means that all questions have high levels of external validity. The coefficient for the total DTS score was very good and equal to 0.883 . 
Table 4. Test-retest reliability.

\begin{tabular}{|c|c|c|}
\hline Questions & Intraclass correlation coefficients & $95 \% \mathrm{CI}$ \\
\hline DTS total scale & 0.883 & $0.826-0.922$ \\
\hline Feeling unreal or cutoff from the world & 0.779 & $0.671-0.852$ \\
\hline Things look flat as if looking at a picture & 0.686 & $0.531-0.790$ \\
\hline Body feels as if it didn't belong to oneself & 0.664 & $0.498-0.775$ \\
\hline Not feeling frightened in normally frightening situations & 0.586 & $0.382-0.722$ \\
\hline Favorite activities no longer enjoyable & 0.603 & $0.407-0.734$ \\
\hline Feeling of being a detached observer of oneself & 0.583 & $0.378-0.721$ \\
\hline Flavor of meals no longer gives a feeling of pleasure or distaste & 0.778 & $0.668-0.851$ \\
\hline Body feels very light as if it were floating on air & 0.792 & $0.689-0.861$ \\
\hline No emotions felt when weeping or laughing & 0.791 & $0.688-0.860$ \\
\hline Feeling of not having any thoughts at all & 0.700 & $0.552-0.799$ \\
\hline Own voice sounds remote and unreal & 0.714 & $0.573-0.808$ \\
\hline Feel like hands or feet becoming bigger or smaller & 0.647 & $0.473-0.763$ \\
\hline Surroundings feel detached or unreal & 0.763 & $0.647-0.841$ \\
\hline Recently done things feel as if they took place a long time ago & 0.717 & $0.578-0.811$ \\
\hline See oneself outside as if looking in a mirror & 0.741 & $0.613-0.826$ \\
\hline Personal memories feel as if one had not been involved in them & 0.741 & $0.613-0.826$ \\
\hline When in a new situation. feeling as if it had happened before & 0.743 & $0.616-0.828$ \\
\hline Unable to feel affection towards family and friends & 0.694 & $0.544-0.795$ \\
\hline Objects look smaller or further away & 0.722 & $0.586-0.814$ \\
\hline Unable to feel properly things touched with hands & 0.805 & $0.709-0.869$ \\
\hline Unable to picture things in mind & 0.615 & $0.426-0.742$ \\
\hline Feeling detached from bodily pain & 0.839 & $0.760-0.892$ \\
\hline Feeling of being outside the body & 0.795 & $0.694-0.862$ \\
\hline Feeling mechanical and robotic when moving & 0.792 & $0.682-0.861$ \\
\hline Smell of things no longer gives feeling of pleasure or dislike & 0.805 & $0.710-0.870$ \\
\hline Detached from own thoughts like they have life of their own & 0.748 & $0.624-0.831$ \\
\hline Urge to touch oneself to be reassured of body existence & 0.836 & $0.755-0.890$ \\
\hline Unable to feel hunger or thirst & 0.731 & $0.599-0.820$ \\
\hline Previously familiar places look unfamiliar & 0.689 & $0.535-0.791$ \\
\hline
\end{tabular}

\section{Criterion based validity}

In order to investigate the criterion based validity of the DTS scale we compare it against the SCL-90 and EPQ scale. The DTS scale presents highly correlation with the SCL-90 and all subscales $(\mathrm{P}<0.0001)$. Also DTS scale correlated highly with N. E and L subscales of EPQ scale (Table 5).

\section{Discussion}

At this study the Greek version of DTS was obtained by translated the self-rating Davidson Trauma Scale diagnosing and measuring frequency and severity symptoms in post-traumatic stress disorder (PTSD). The translation process was relatively straightforward with only small differences between the original and the backtranslated version of the questionnaire. The Greek version of DTS scale. presents good internal consistency with Cronbach's $\alpha=0.930$ and Guttman split-half coefficient
Table 5. Correlation of DTS with SCL-90 and EPQ scales.

\begin{tabular}{lccc} 
& \multicolumn{2}{c}{ Total DTS score } & \\
& N & P & \\
EPQ scale & & & \\
$\quad$ Psychoticism & 291 & 0.048 & 0.411 \\
Neuroticism & 291 & $-0.159^{* *}$ & 0.000 \\
Extraversion & 291 & $-0.243^{* *}$ & 0.007 \\
Lie & 291 & & 0.000 \\
SCL-90 scale & & $0.222^{* *}$ & \\
Somatization & 291 & $0.416^{* *}$ & 0.000 \\
Ob-comp & 291 & $0.233^{* *}$ & 0.000 \\
Interper-sens & 291 & $0.395^{* *}$ & 0.000 \\
Depression & 291 & $0.342^{* *}$ & 0.000 \\
Anxiety & 291 & $0.288^{* *}$ & 0.000 \\
Hostility & 291 & $0.367^{* *}$ & 0.000 \\
Phobic anxiety & 291 & $0.322^{* *}$ & 0.000 \\
Paranoid Ideation & 291 & $0.399^{* *}$ & 0.000 \\
Psychoticism & 291 & $0.393^{* *}$ & 0.000 \\
General symptomatic index & 291 & 0.000 \\
\hline
\end{tabular}

* Correlation is significant at the 0.05 level (2-tailed); ${ }^{* *}$ Correlation is significant at the 0.01 level (2-tailed). 
0.878 respectively. The test-retest reliability of DTS was satisfactory with high total intra-class correlation coefficients 0.883 . Individual variables presenting high levels of external validity with intra-class correlation coefficients from 0.583 to 0.839 .

\section{Conclusions}

The Greek DTS presents good criterion base validity by showing significant correlations between the Greek Davidson Trauma Scale with the SCL-90 and EPQ scale. Davidson et al. ${ }^{4}$ presented a factor analysis of the DTS with post-traumatic stress disorder yielded two dimensions also for severity and frequency. In this study we aimed to test this model in a sample of Greek population and found also a two factor structure. The DTS is a validated selfrating scale used in the diagnosis of posttraumatic stress disorder. The psychometric strength of PTSD-Greek version it's reliable for its future use, particularly for screening for subjects with possible diagnosis of PTSD.

\section{References}

1. Davidson JRT, Smith RD, Kudler HS Validity and reliability of the DSM-III criteria for postraumatic stress disorder. J Nrv Ment Dis 1989;177:336-41.

2. Solomon SD, Keane TM, Newman E, Kaloupek DG. Choosing self report measures and structured interviews. In: Carlson EB (ed). Trauma research methodology. Luterville: Sidran Press; 1996. pp 56-81.

3. Davidson JR, Kudler HS, Saunders $\mathrm{WB}$, et al. Predicting response to amitriptyline in posttraumatic stress disorder. Am J Psychiatry 1993;150: 1024-9.

4. Davidson JR, Malik MA, Travers J. Structured interview for PTSD (SIP): psychometric validation for DSM-IV criteria. Depress Anxiety 1997;5:127-9

5. Davidson JR, Book SW, Colket JT, et al. Assessment of a new self-rating scale for post-traumatic stress disorder. Psychol Med 1997;27:153-60.

6. American Psychiatric Association. Diagnostic and Statistical Manual of Mental Disorders. 4th ed. Washington DC: American Psychiatric Association;
1994.

7. Eysenck HJ, Eysenck SBG. Manual of the EPQ (Personality Questionnaire). London: Hodder and Stoyghton Educational; 1975.

8. Dimitriou E. EPQ personality questionnaire. Greek validation in the Greek population. Engefalos 1986;23:41-54.

9 Derogatis L. Melisaratos N. The brief symptom inventory: an introductory report. Psychol Med 1983;13:595-605.

10. Donias S, Karastergiou A, Manos N. Validation of the symptom checklist-90$\mathrm{R}$ in Greek Population. Psychiatriki 1991;2:42-8.

11. Field AP. Discovering statistics using SPSS (3rd ed.) London: SAGA; 2009.

12. Cronbach LJ. Coefficient alpha and the internal structure of tests. Psychometrika 1951;16:297-334.

13. Guttman L. A basis for analyzing testretest reliability. Psychometrika 1945;10:255-82.

14. Koch G. Intraclass correlation coefficient. In: Kotz S, Johnson NL, (eds). Encyclopedia of statistical sciences. 4th ed. New York: John Wiley \& Sons: 1982. pp 213-217. 